Review

\title{
The Review of Mark Planning Problem
}

\author{
Kritsada Puasakul ${ }^{\mathrm{a}}$ and Paveena Chaovalitwongse ${ }^{\mathrm{b}, *}$ \\ Department of Industrial Engineering, Faculty of Engineering, Chulalongkorn University, Bangkok, \\ Thailand \\ E-mail: akritsada.p2525@gmail.com, bpaveena.c@chula.ac.th (Corresponding author)
}

\begin{abstract}
Mark planning is one of the most important planning processes in garment industry. The major function is to generate a set of markers which is used as cutting guidelines or cutting templates in a cutting process. In other words, this process can be seen as a planning step of a cutting process which determines what sequence and how many parts will be cut. For the academic point of view, mark planning has been of interests for more than 15 years. Many papers are published with various objective functions, problem scenarios, and constraints. Therefore, key content summary of these papers are useful for researchers who are interested in this type of problem. The purpose of this paper is to introduce an exhaustive review of mark planning papers which is composed of three sections: the relevant background, the summary of reviewed papers, and the relationship between objective functions which is cost combinations and major garment characteristics. In conclusion, future researches should go forward the trend of integration between this process and other relevant processes in the production chain, e.g. cut scheduling, assembly planning, marker making.
\end{abstract}

Keywords: Mark planning, review, marker, garment characteristics, the basic mark planning model.

ENGINEERING JOURNAL Volume 20 Issue 3

Received 22 July 2015

Accepted 26 October 2015

Published 19 August 2016

Online at http://www.engj.org/

DOI:10.4186/ej.2016.20.3.91 


\section{Introduction}

In garment industry, fabric rolls are processed into the desired finished goods. Figure 1 shows flow of garment processes as well as flow of materials. The cutting process, the function of this process is to cut fabric rolls into bundles of required cut pieces or parts. The sub-assembly process, the function of this process is to sew cut pieces into semi-product, e.g. sleeves, collars. This process usually appears with manufacturers who produce medium to high complex products. Finally, the assembly process, the function of this process is to assemble semi-products into the desired products. All garment products must be sequentially processed on these three processes to become the finished products.

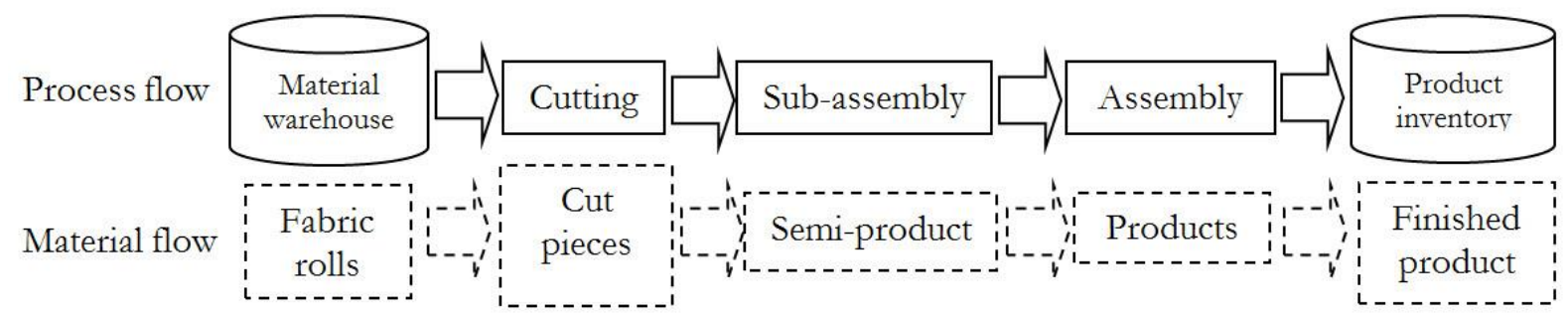

Fig. 1. The flow in garment industry.

A cutting process is an upstream process which generates bundles of cut pieces used as an input to all other downstream processes. Apparently, a cutting process controls sequence of jobs that will be processed, and a production smoothness in the downstream processes. Hence, this process should be efficiently managed with systematic method.

In garment industry, a mark planning process is used to plan for cutting process. The function of this process is to generate a set of markers which are used as cutting guidelines or cutting patterns in a cutting process. By definition, mark planning process can be defined as follows:

(1) Mark planning process is to arrange cut templates to execute the fabric cutting operation [1];

(2) Mark planning is to find an optimal combination of markers to cover the work order [2];

(3) Mark planning is to determine the set of cut templates needed including the garment sizes in each cut template, quantities of garments from each size and number of fabric plies will be cut under each cut template [3];

(4) Marker planning is the process of arranging all the patterns of the component parts of one or more garments on a piece of paper [1].

Data input into mark planning process is a customer order which consist of order detail, bill of material, and assembly chart. Generally, a customer order comprises of two dimensions, namely, size and color. An output from this process is a set of markers which are indicated by 3 important questions [4] as follows:

(1) Which part should be assigned to which marker with how many copies?

(2) How many fabric plies is appropriate for each marker?

(3) How many markers should be used to satisfy demand?

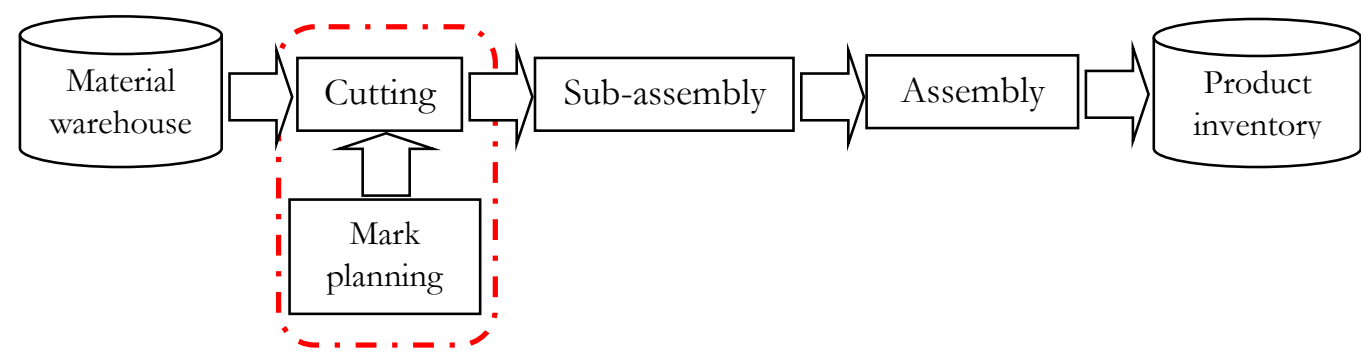

Fig. 2. The flow of garment processes with mark planning.

As can be seen in Fig. 2, a set of makers which is an output of mark planning process is cut into many bundles of parts in a cutting room. These bundles are subsequently, sewn into the desired products in sub- 
assembly and assembly process. Therefore, mark planning can be seen as planning step which partially controls what and how many parts to cut which, also, controls production sequence and smoothness of sub-assembly and assembly process. Apparently, an output of mark planning can affect to the performance of the whole system.

The current mark planning methods used in industry range from manual ad hoc procedures to customized proprietary software [5]. However, many apparel manufacturers prefer to use a planner's experience or commercial software in generating this marking plan.

From literature survey, many MP papers published continuously over the last 15 years. These papers are written with various assumptions, objective functions, solution approaches, and performance measurement methods. Especially, there are variety of solution approaches used which are ranged from an exact enumerative to meta-heuristic, e.g. GA, SA. The summarization of these papers can help researchers systematically review mark planning problem and, subsequently, find research gaps that can be extended to new researches.

The purpose of this paper is to present a review of mark planning papers which the contents are represented in five dimensions, namely, objective function, constraint, model formulation, solution approach, and performance measurement. To provide the basic knowledge of mark planning process for readers, the relevant background is drawn in the early section. Moreover, the relations between each objective function which is a combination of costs and a set of major garment characteristics are explained in the later section.

The benefits of this reviewed paper can be concluded as follows:

(1) To researchers who are interested in mark planning research, this reviewed paper will provide the necessary knowledge beginning with the basic knowledge and ending up with the summarization of mark planning papers. This knowledge will helps researchers to understand the relevant background and the current trend in mark planning research. Consequently, they can find gaps and motivations for future researches in this area.

(2) The relations between objective functions and major garment characteristics will tell readers what are cost drivers for each cost combination. Obviously, these cost drivers directly control values of the related cost component. Clearly understanding these cost drivers will helps readers successfully control each cost combination. On the other hand, these relations will tell readers what costs are most probably occurred when facing with each combination of characteristics.

In the next section, some necessary basic knowledge of mark planning process is explained. Beginning with what is mark planning, all dimensions of this process are clearly described. Subsequently, standard mathematical model and incurred cost are explained. In section 3, the details of mark planning papers are reviewed and represented in five categories. In section 4, the relations between objective functions and major garment characteristics are explained. In section 5, conclusion is drawn. Finally, reference is provided in section 6 .

\section{The Relevant Background}

In mark planning process, there are many specific terms used which can confuse readers that are not familiar with a garment industry. To well understand this paper, readers should get familiar with the following terms. The purpose of this section is to explain the major terms used in mark planning process.

\subsection{Marker}

A marker is a combination of parts arranged on a rectangular shape block which is later used as a cutting guideline or cutting pattern in a cutting process. In [6], marker is defined as garment pattern pieces of different sizes and styles that are laid out on a sheet of paper with fixed width and arbitrary length in order to achieve the highest marker efficiency. In each marker, many parts are arranged so as to achieve the desired objective. After parts were completely arranged, fabric area used, waste area and remaining area are calculated. The fabric area used is equal to total area of parts assigned to that marker plus waste area. The waste area which can be divided into two types with respect to its causes of occurrence. One is occurred from a shape of parts that are not rectangular. The other one is occurred from a cutting restriction [7]. Finally, the remaining area is equal to a maximum allowable area subtract by total area of parts assigned to that marker. 
A marker in garment industry is the same as a batch in other manufacturing industries. Saifallah [8] states that processing parts in batches is preferable to the processing when setup times are significant. In the same way, parts are combined to create marker or batch in order to reduce set up occurred in generating and using that marker.

Furthermore, markers can be categorized into three groups with respect to the required sizes in customer demand table. Firstly, markers that have only one size, e.g. S-S-S, M-M-M and etc. Secondly, markers that have at least two sizes which all sizes are absolutely different, e.g. S-M-L, M-L-XL and etc. Finally, markers that have at least two sizes which some sizes are repeatedly used on the same marker, e.g. S-S-M, M-M-L and etc.

On the top of each marker, there is a marker's pattern which is a combination of parts from one size or many sizes. Furthermore, this pattern is affected by four factors, i.e. number of sizes required in a customer order, total number of units required, the distribution of demand to all sizes and number of plies used in each marker.

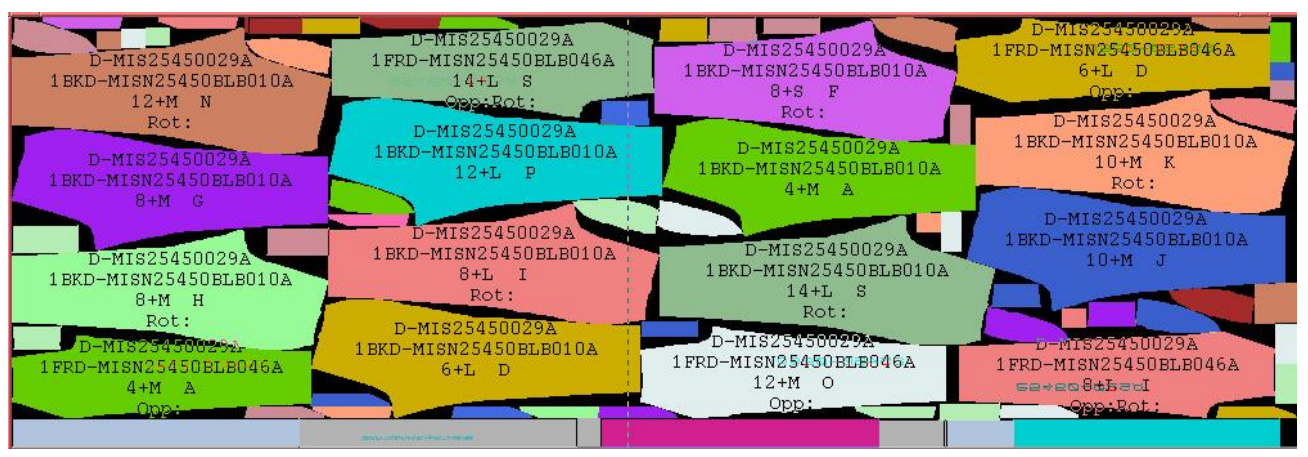

Fig. 3. Example of marker pattern.

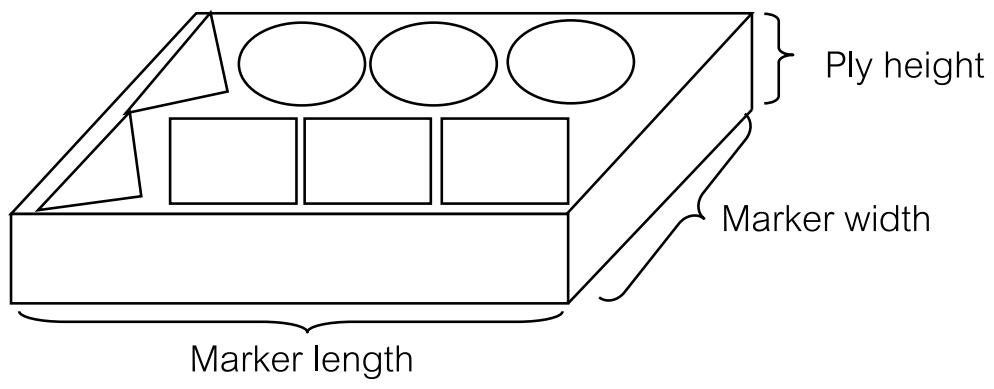

Fig. 4. Example of marker.

Each marker can be described by three dimensions, namely, length, width and height. Marker width is varied depending on a width of fabric roll used which is typically assumed to be constant in many researches $[9,10]$. A length of each marker is restricted to some specific upper bounds which its value depending on a planner or a cutting table length. Generally, ply height is restricted to two values which correspond with equipment limitations. One is lower bound whereas the other one is upper bound on ply height. In some researches, ply height can compose of different color fabrics which is called "multi-color marker" $[10,11]$ while in practical situation, it is hard to manage different color parts that are cut out simultaneously.

In most papers, demand input used to create markers is tabulated as shown in Table 1.

Table 1. Demand table.

\begin{tabular}{|c|c|c|c|}
\hline Colour Size & $S$ & M & $\mathrm{L}$ \\
\hline Black & 100 & 50 & 50 \\
\hline Green & 150 & 50 & 100 \\
\hline
\end{tabular}


In Table 1, there are two colors (black and green) and three sizes (size S, M, and L). The intersection between size and color represents a demand quantity of a specific color and size.

In each marker, there are many area involved as described below:

(1) Total assigned part area - this area is the summation of all part areas that are assigned to the considered marker.

(2) Waste area - due to irregular shape, some assigned parts may not completely fit to others on the same marker. An inevitably unused area between or among these parts are considered as waste area.

(3) Remaining area - remaining area is a difference between the maximum allowable area which correspond with a cutting table area and a total assigned part area.

(4) Allowance area - these areas are located on head and tail of each marker. Marker locking equipment are placed on these two areas to lock a marker with a cutting table.

(5) Total area of marker - this area is the summation of total assigned part area, waste area, and allowance areas. Therefore, this area is equal to total fabric used for one ply of each marker.

\subsection{Mark Planning}

Figure 5 shows a flow of data from a customer order to mark planning process. The flow begins with a customer order which composes of three important data. Firstly, order detail, this data is usually represented in the form of table. Rows of table are colors of the desired product while columns are sizes. Numbers of demand for each size and color are in the table. Secondly, bill of material (BOM), this data tells planner what parts and how many of each part are needed to assemble to the desired product. In some products, bill of material is very complex and is drawn in the form of hierarchy which each level represents intermediate products or work in process (WIP), e.g. shirt, overcoat. Thirdly, assembly chart, this data shows how to assemble cut parts into the desired product. It also gives detail of operation sequence and production lead time. An input of mark planning process is called demand table which is a combination of order detail and bill of material. In demand table, demand quantities are in unit of part, e.g. part 1 and size $S$, part 2 and size L. The output of mark planning process is a set of markers which will be used later as cutting guidelines in a cutting process. Furthermore, quantities of parts derived from this set of markers must satisfy a demand quantity in a demand table.

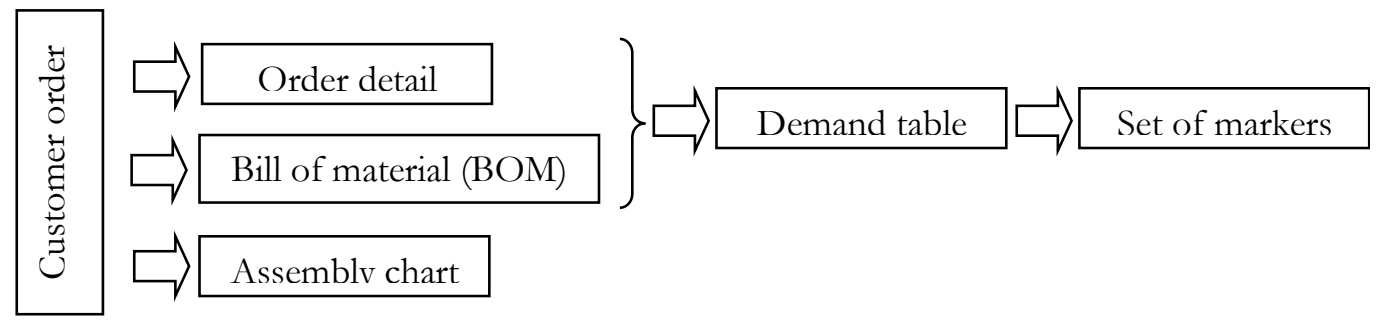

Fig. 5. Flow of data of mark planning process.

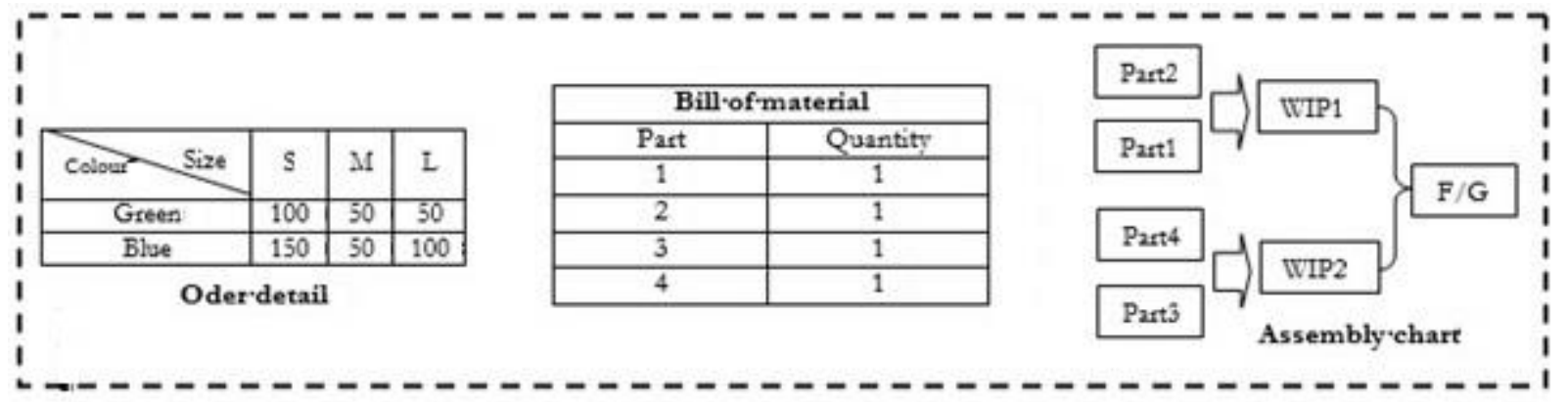

Fig. 6. Examples of order detail, bill of material, and assembly chart.

Figure 7 shows an example of demand table and a partial output from mark planning process. The purpose of this chart is to demonstrate demand table and marker details. Therefore, some relevant data are 
not shown in this chart. The marker details can be read as follows. Marker 1 is composed of 30 plies of fabric. The marker is patterned to include one copy of part 1 size $S$, three copies of part 2 size $S$, two copies of part 1 size M, and one copy of part 3 size L. Marker 2 is composed of 25 plies of fabric. The marker is patterned to include two copies of part 1 size M, one copy of part 2 size M, one copy of part 1 size L, and four copies of part 2 size L. However, there can be many alternative marker configurations that can be generated from this demand table.

The major function of mark planning process is to generate a set of markers that are used as cutting guidelines in a cutting process. Furthermore, it consists in dividing every garment's order into sections, assigning the sizes to them, and determining their lengths and numbers of layers such that the total fabric length is minimized [9].

This process is very helpful and useful in the situation that numbers of parts required are very large. In such situation, efficient plan is relatively hard to compute with traditional manual method. To illustrate mark planning process, demand input in Table 1 is transformed to markers with a simple method which is usually used in industrial practice.

Conceptually, this simple method tries to eliminate number of color-size demand entities by each generated marker to simplify the problem. First of all, two $S$ and one $M$ are assigned to marker 1 . The last black color demand is size $\mathrm{L}$ which should be assigned to marker 2. Subsequently, the green color is considered, beginning with three $\mathrm{S}$ are assigned to marker 3. Lastly, one of size $\mathrm{M}$ and two of size $\mathrm{L}$ are assigned to marker 4. All ply heights are equal to 50 which is the maximum allowable ply height. The resulted marking plan with four markers is shown in Table 2.

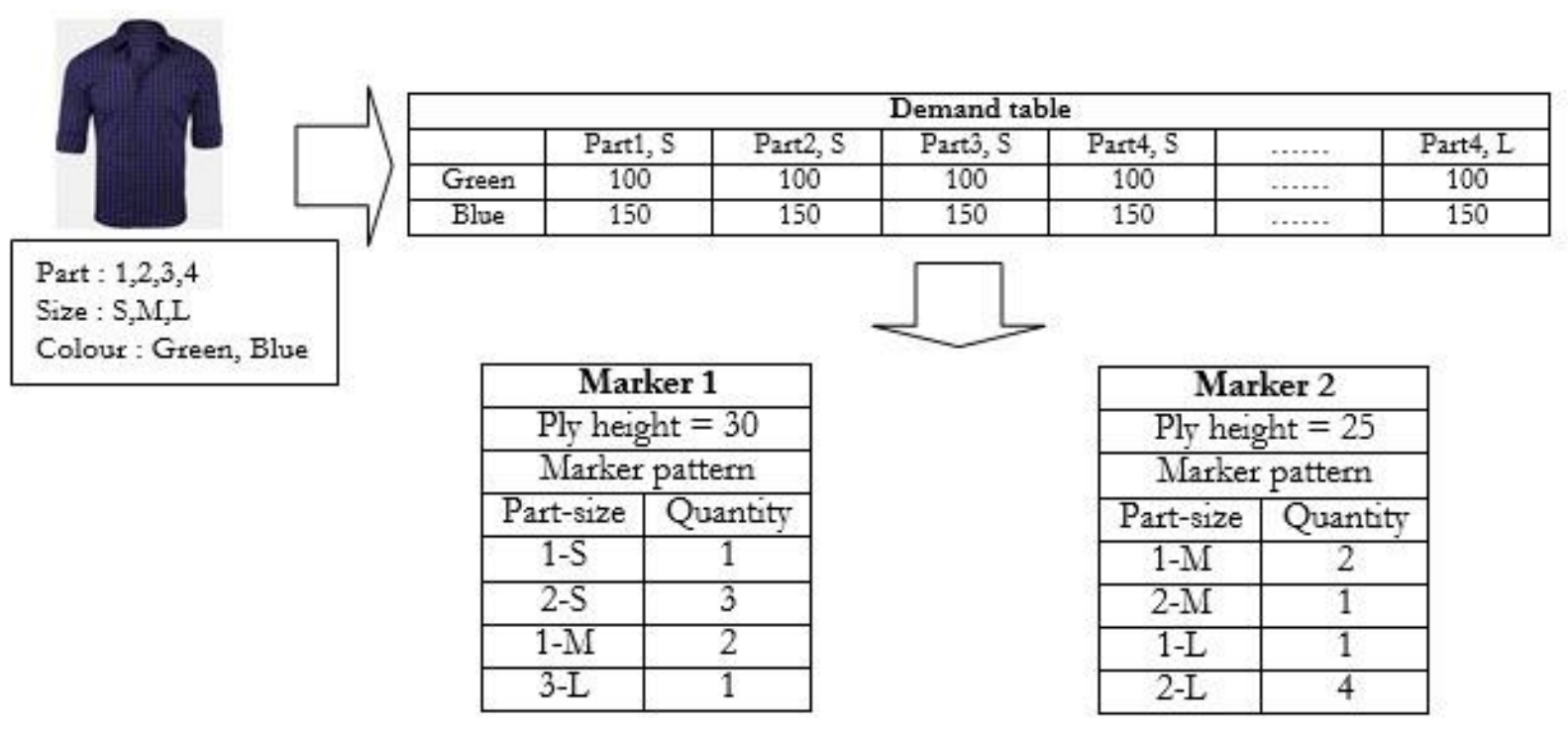

Fig. 7. A numerical example of demand table and markers.

Table 2. Output table.

\begin{tabular}{cccc}
\hline Marker no. & Colour & Pattern & Ply \\
\hline 1 & Black & S-S-M & 50 \\
2 & Black & L & 50 \\
3 & Green & S-S-S & 50 \\
4 & Green & M-L-L & 50 \\
\hline
\end{tabular}

In Table 2, there are four markers used (with no waste area and excess unit occurred) to satisfy a customer demand. This marking plan is feasible with respect to the area and ply height limitation. However, there are many feasible marking plans besides this result.

The previously shown example is quite small compared to real industry demands. In practical, for each customer order, more than four markers have to be used. Therefore, this planning process is further complicated when facing with larger customer orders. 
In industrial practice, this process mostly relies on planner experiences which usually result in feasible but not optimal solution [12]. Planners try to combine smaller size units with larger size units because sometimes smaller size units can be inserted into unused space between larger size units. Moreover, they try to assign parts as many as possible to each marker to maximize material utilization. They solely focus on material utilization or amount of fabric used per one customer order. Additionally, in many cases, planners often use the same marker patterns repeatedly with different customer demands which require the same product and sizes but difference in total number of units required and the distribution of demand. As a result, it can cause many excess units which are seen as additional cost in some situations.

In academic point of view, mark planning problem has been interested for more than 15 years. Almost researches found are based on the similar scope and assumptions of the problem. The major differences are their objective functions and solution approaches. These differences will be explained in detail in the section 3 and 4. However, most of papers found are extended from the basic model which is formulated as integer nonlinear programming model (INLP.). The details of the model are presented as follows:

Set:

I set of all required parts.

$\mathrm{K}$ set of all markers

\section{Decision variable:}

$\mathrm{X}_{\mathrm{ik}}=$ integer $=$ number of copies of part $\mathrm{i}$ in marker $\mathrm{k}, \forall \mathrm{i}$ in $\mathrm{I}, \forall \mathrm{k}$ in $\mathrm{K}$. This decision variable is used to answer the question "Which part should be assigned to which marker with how many copies?".

$\mathrm{Y}_{\mathrm{k}}=$ integer $=$ number of plies of marker $\mathrm{k}, \forall \mathrm{k}$ in $\mathrm{K}$. This decision variable is used to answer the question "How many fabric plies in each marker?".

$Z_{\mathrm{k}}=$ binary $=1$ if marker $\mathrm{k}$ is selected.

$$
0 \text { otherwise, } \forall_{\mathrm{k}} \text { in } \mathrm{K} \text {. }
$$

This decision variable is used to answer the question "How many markers should be used to satisfy demand?"

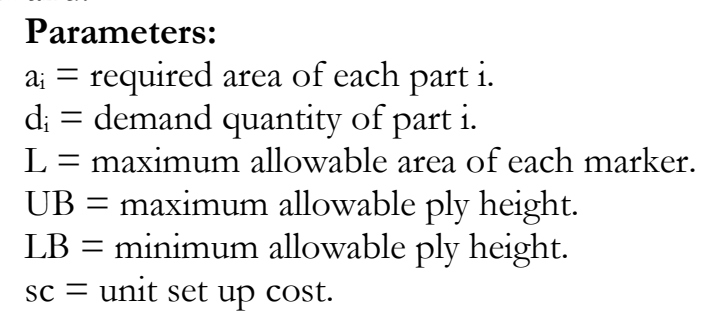

$$
\begin{gathered}
\min \left[\left(s c \times \sum Z_{k}\right)\right] \\
\sum k\left(X_{i k} Y_{k}\right) \geq d_{i} ; \text { for all } i \\
\sum i\left(X_{i k} \times a_{i}\right) \leq L \times Z_{k} ; \text { for all } k \\
Y_{k} \geq L B \times Z_{k} ; \text { for all } k \\
Y_{k} \leq \mathrm{UB} \times Z_{k} ; \text { for all } k
\end{gathered}
$$

Eq. (1), the objective function is to minimize set up cost which is the product of total number of markers used and unit set up cost. Eq. (2) satisfy demand constraint stated that total number of cut parts must greater than or equal to the demanded parts. Eq. (3) max area limitation stated that the total used area must less than or equal to the maximum allowable marker area which is equal to the available cutting table length multiplies by the average width of all fabrics rolls used. This area is mostly assumed to be constant value. Eq.(4) and Eq.(5) maximum and minimum allowable ply height restriction. This height range from the lower allowable to the upper allowable which both correspond with the equipment limitation. This limitation depends on the type and performance of cutting machine used.

The structure of this problem can be viewed as an extension of the multiple knapsack problem (MKP) which is the problem of assigning a subset of $\mathrm{n}$ items to $\mathrm{m}$ distinct knapsacks, such that the total profit sum 
of the selected items is maximized, without exceeding the capacity of each of the knapsacks [14]. Readers who are interested in mark planning problem can start the study with this problem.

Furthermore, there are common assumptions that are usually addressed in many papers as stated below:

(1) All parts of a product must be simultaneously assigned to the same marker.

(2) Total area or length of all required parts of any product is equal for all sizes.

(3) The width of all fabrics used is constant for all markers.

Alan A. Farley [13] proposes relatively different models based on cutting-stock problem. He states that an objective of mark planning problem should be maximization of long-run profitability rather than minimization of only waste. He proposes two alternative models to represent this idea. Moreover, his proposed models incorporate all relevant costs, contributions and, constraints ranging from fabric warehouse to sewing process. These models are very complex and hard-to-use in real-world industry situation. However, these complex models can be seen as examples or frameworks for development of more sophisticated models.

\subsection{Costs Incurred in a Mark Planning Process}

\subsubsection{Setup cost}

This cost is a combination of labor cost occurred when markers are generated and used, and opportunity cost which is proportional to number of markers used. Additionally, this cost is almost occurred in 4 activities as explained below:

(1) MP process - this process is time-consuming process which its operation time grows with number of markers used. Planners must decide marker's configurations which are varied depending on how large of a customer demand, criteria used and range of parameters values.

(2) Marker making process - there are two main activities in marker making room. Firstly, all parts in each marker pattern generated in MP process are arranged so as to maximize material utilization. This operation is operated in 2 steps which are by commercial software at first and further adjusted by operator. Finally, all completely adjusted markers are printed by a special printer. In this operation, tasks of operator are to set up printer, feed papers and roll up all printed markers.

(3) Cut scheduling process - the functions of this process are to assign markers to cutting tables and, then, sequence these markers on each cutting table. Operation time again grows with number of markers used and number of available cutting tables.

(4) Spreading and cutting - all markers from MP process are orderly spread and cut with respect to a schedule from cut scheduling process. In some large factories, this process is executed by a computerized cutting machine which incurs machine cost or electricity cost instead of labor cost. Lastly, all cut out stacks are split into proper size bundles.

Apparently, this cost is labor cost expected to occur in four explained processes. Their operation times are mainly proportional to number of markers used. Therefore, operation times are increased if number of markers used are increased and vice versa.

\subsubsection{Excess cost}

This cost is fabric cost occurred when cut out parts or units are over a customer demand amount. Moreover, it is usually occurred with original equipment manufacturers (OEM.) because, in this type of manufacturer, amount of demand are decided and fixed by customers.

When demand is not smooth (large differences between demands of each size) and a planner try to use as minimum as possible number of markers, excess units are usually occurred. It can be seen as a trading off between excess units and number of markers used. An example of non-smooth demand and output are shown in Table 3 and 4, respectively.

Table 3. Example of non-smooth demand.

\begin{tabular}{|c|c|c|c|}
\hline Colour Size & S & M & $\mathrm{L}$ \\
\hline Pink & 60 & 20 & 95 \\
\hline
\end{tabular}


Table 4. Output of non-smooth demand (excess).

\begin{tabular}{cccc}
\hline Marker no. & Colour & Pattern & Ply \\
\hline 1 & pink & S-M-L & 20 \\
2 & pink & S-L-L & 40 \\
\hline
\end{tabular}

From Table 4, 60 S, $20 \mathrm{M}$, and $100 \mathrm{~L}$ are produced. As a result, five excess units of size $\mathrm{L}$ are occurred. However, these excesses can be eliminated by adding a new marker to the output in Table 4 as shown in Table 5. This can be seen as trading off between excess cost and set up cost which can be happened if it is worthwhile.

Table 5. Output of non-smooth demand (no excess).

\begin{tabular}{cccc}
\hline Marker no. & Colour & Pattern & Ply \\
\hline 1 & pink & S-M-L & 20 \\
2 & pink & S-L & 40 \\
3 & pink & L & 35 \\
\hline
\end{tabular}

\subsubsection{Material cost}

This cost is the cost of total fabric used which is the main material of all garment products. The difference between this cost and excess cost is that, in excess cost, only over-demand parts are seen as cost whereas material cost concerns all fabrics used which includes demand parts, excess parts, waste fabrics and allowance in both tails of markers.

In industrial situation, most planners believe that the total fabrics used can be reduced by combining small size units with large size units. Small size units will be inserted to gaps between large size units. Specifically, this phenomenon always happens with complex products, e.g. shirt, suit, and etc, because these products comprise of parts with various sizes.

With emphasis on this cost, planners try to use combinations of parts or units that result in minimum amount of fabrics used. In many researches, they firstly generate a set of possible combinations and, subsequently, try to select a subset of combinations that both satisfy a customer demand and result in minimum fabrics used.

\subsubsection{Machine cost}

Machine cost is an electricity cost occurred in a cutting process. Moreover, this cost is proportional to the length of fabric used to satisfy each customer demand. Generally, this length is proportional to demand volume. Hence, machine cost is also proportional to demand volume. In large factories, it is worthwhile to use computerized cutting machine instead of operators. Two main reasons are 1.machines can operate faster than operators and 2.it has higher accuracy than operators. The disadvantages of using machine are 1.this machine is relatively expensive and 2.skill operators are required to control this machine. In practical situation, it can be seen as trading off between labor cost and machine cost.

\section{The Major Characteristics of Garment Industry}

From industrial survey and review of many mark planning papers, four major garment characteristics are found to be most important. These four characteristics are directly related to four main sources of costs in mark planning process as stated below:

(1) Number of markers used is proportional to amount of demand volume. This means high demand volume can result in large number of markers used.

(2) A possibility of excess parts to occur is related with variation of demand between sizes. This means high variation of demand between sizes can cause number of excess parts. 
(3) The price of fabric is directly related to both cost of excess occurred and cost of total fabric used for each customer order. If the price of fabric is relatively low, both previously mentioned costs can be dominated by other relevant costs and vice versa.

(4) In many researches, amount of fabric used for each marker can be additionally reduced by combining small-size parts with large-size parts. Small-size parts will be inserted into gaps between large-size parts. This means when number of parts per unit of product is high, amount of fabric used can be possibly reduced.

Manufacturers that have different combination of characteristics emphasize on or incur different combination of costs. Subsequently, manufacturers incurred different combinations of costs should emphasize on different points in generating and using markers. The 4 major characteristics of garment industry are described as follows.

\subsection{Demand Volume}

This character is referred to the amount of units in customer orders which the manufacturer usually receives. This amount of demand can be varied depending on scale and type of manufacturers. For example, it can be 20-100 units for manufacturers in fashion industry or it can be 5,000-10,000 units for mass production manufacturers.

As stated earlier, MP process is to determine set of markers used to satisfy a customer order. However, each marker can contain limited number of parts or units with respect to the area and ply height constraints. Therefore, number of markers used is proportional to amount of units in a customer demand which means more markers are needed when an order is larger.

In some cases, when amount of demand units are relatively high, such as in mass production, large number of markers will be used which result in high set up cost occurred. In situation like this, set up cost will probably dominate other relevant costs. Accordingly, other costs except set up cost can be neglected from the consideration.

Moreover, in large-size factory where customer demands usually come in huge lot size, a manual spreading and cutting method may be replaced with a computerized cutting machine. With a computerized machine, markers can be spread and cut faster and more accurate than a manual method. Therefore, set up cost occurred in a manual method becomes electricity cost in a computerized method.

Finally, demand volume can be categorized into two levels as described below:

(1) High demand volume - in this level, customer demands usually come in large-size lots. Additionally, these amounts of demands often occur in mass production factories [15].

(2) Medium demand volume - in this level, customer demands usually come in medium-size lots. Moreover, these amounts of demands often occur in medium size factories.

(3) Low demand volume - in this level, customer demands usually come in small-size lots. Furthermore, these amounts of demands often occur in fashion product factories which are very small compared to the factories in level 1 and 2.

\subsection{Variation of Demand Between Sizes}

In this research, a demand variation is referred to a distribution of demand quantity to all required sizes of each customer order. As stated previously, many parts or units must be combined together to generate markers, However, if the distribution of that demand is not smooth, some combinations can inevitably cause excess parts or units. Roughly, an amount of excesses depends on a degree of non-smoothness of the considered order. Obviously, this character is strongly related to a possibility of excess to occur. A smooth demand pattern has less possibility of excess to occur whereas a non-smooth demand pattern can result in many inevitable excesses. With a non-smooth demand, excess cost should be incorporated into an objective function. Moreover, a non-smooth demand also directly effects to marker generation process. It is harder to decide marker pattern and ply height of each marker. With unit excess cost higher enough, number of markers used can be increased to trade-off with reducing in excess cost.

From industrial survey, this non-smooth demand usually takes place when customer repeatedly orders the same order again and again. Moreover, this non-smoothness is more effective when combining with the attempt of planners to minimize number of markers used or set up cost. In this situation, sizes that have 
different demand quantity may be assigned to the same marker if their combination can increase material utilization. The demand variation can be divided into 2 types as follows.

(1) A smooth demand - in this group, differences between demands of each size are relatively small compared to amount of demand in all sizes. Additionally, the quantity of demand of each size is approximately close to the averaged value of all demands from all sizes. Marking plans generated from such demands tend to have lower excesses. Therefore, this smooth demand pattern insignificantly affects to mark planning cost.

(2) A non-smooth demand-in this group, differences between demands of each size are large compared to amount of demand in all sizes. The quantity of demands of all sizes are fluctuate which certainly increase a possibility of excess to occur in marking plan. Marking plans generated from such demands tend to have higher excesses. Obviously, this non-smoothness can significantly increase a possibility of excess to occur.

\subsection{The Price of Fabric Used}

In garment industry, there are variety types of fabric with respect to their price. This characteristic focuses on the price of fabric used by manufacturers. However, prices are categorized into two groups, namely, high fabric cost and low fabric cost. Additionally, the words "high price" and "low price" are referred to high and low price when compared to the level of labor cost in the considered companies.

As stated previously, fabric is the main material for producing any garment. Obviously, price of fabric and material cost are strongly related to each other. For manufacturers who use high price fabrics, material cost in terms of both excess and all fabric consumption plays important role in total cost calculation. A high price fabric increase a value of both total fabric used for all demand and amount of fabric used for excess parts. This will make material cost and excess cost more important. Therefore, they should be incorporated into an objective function. Additionally, in situation where demand is very low and the price of fabric is relatively high, fabric cost in terms of both material and excess cost can dominate all other relevant costs.

(1) High fabric cost - in this group, a unit fabric cost is relatively high compared to a unit labor cost. Obviously, manufacturers have to pay attention to both amount of fabrics used and number of excesses occurred. Therefore, a material cost should be included in the objective function. Manufacturers in this group usually produce well-known brand name products such as item in fashion industry, product of ADIDAS, NIKE and etc.

(2) Low fabric cost - in this group, a unit fabric cost is small compared to a unit labor cost. Hence, a material cost can be neglected from the consideration. Manufacturers in this group usually produce low price products.

\subsection{Number of Parts Per Unit of Product}

There are variety of products such as outwears, underwear, headwear, footwear, belts, ties and etc. Each product can be different in style, color, type of fabric used, shape, number of parts required and etc. Even in the same product, there can be many differences depending on designers and customers.

This characteristic focuses on a complexity of product with respect to their number of parts required and the variety of their shapes and sizes. Products with a large number of parts with high variety of shapes and sizes are classified as complex products whereas products with a small number of parts with low variety of shapes and sizes are seen as simple products. Examples of complex products are man and woman shirt, suit and etc. Examples of simple products are t-shirt, shorts, pants and etc.

Generally, complex products consist of a large number of parts with variety of shapes and sizes which can be combined together to generate markers efficiently. Especially, when small parts are combined with large parts, some small ones can be inserted into gaps between large parts. As a result, amount of fabric used in terms of total area or total length can be reduced. Apparently, this characteristic is directly related to total amount of fabric consumption and, subsequently, to material cost. With simple products, total fabric used has small chance to reduce whereas, with complex products, total fabric used has higher chance to reduce. Obviously, with complex products, material cost has a room to improve. Therefore, this cost component should appear in an objective function. Two types of products are explained as follows: 
(1) High number of parts - products in this group consist of many parts which are varied in size or area of fabric required and shape of parts. Therefore, small parts can be inserted into the gaps between large parts to reduce total amount of fabric used.

(2) Low number of parts - products in this group consist of a few parts which mostly are large parts. Hence, insertion between parts is difficult to happen.

As explained before, these characteristics are certainly related to costs incurred in mark planning. Thus, in section 5 , the relationships between these characteristics and the objective functions found in literatures are clearly described.

\section{The Review of Mark Planning Papers}

In this section, mark planning papers are summarized and presented by five model components. In each model component, important details are explained clearly. The first component, objective function, there are four major objectives found. The second component, constraint, a set of standard mark planning constraints is described. Moreover, additional constraints addressed in some papers are also explained. The third component, model formulation, there are many types of model used to formulate this problem ranged from nonlinear model to linearized model. The fourth component, solution approach, these approaches can be divided into two broad groups with respect to their purpose of use. The first group is relaxation methods and the second group is optimization methods. The last component, performance measurement, there are 2 important issues which are sources of problem instances and lower bounds.

\subsection{Objective Function}

There are four major objectives found which each objective function composes of a set of costs. The first objective function is minimization of set up cost. This objective is represented in three forms which are all nearly the same in meaning. Firstly, it is directly represented in the form of minimum number of markers or lays used [16-18]. When numbers of markers are tried to minimized, number of units in each marker should be maximized. Therefore, the second form is maximum number of units in each marker $[3,19]$. Naturally, mark planning is an iterative process which each iteration try to satisfy a customer demand with a generated marker. Hence, to minimize number of markers used, each iteration should generate a marker that can maximize number of eliminated pieces from a work order [2].

However, these three objective functions are probably different when using. Fister et al. [20] argue that "maximizing number of eliminated pieces at each step does not lead to a minimum number of markers or lays to cover the work order". Therefore, using minimum number of markers as objective function has more chance of leading to the desired target.

The second objective function is minimization of set up plus excess cost [10, 21, 22]. At first, the objective is to minimize these two costs simultaneously but this objective is difficult to solve. To simplify this difficulty, in $[10,21]$, they use mathematical equation to calculate the minimum number of markers used to satisfy a customer demand. Subsequently, they fix a number of markers in model to this minimum number. The objective function of these papers is reduced to minimize only excess cost. Furthermore, this excess cost is represented in the form of a number of units produced which is used to show the attempt to minimize the gap between produced quantity and demand quantity. Especially in [23], the authors add an objective component that is used to represent a variation of due date in each marker. This objective component is in the form of standard deviation of due date of each marker. When this time based component is added to the objective function, the original problem becomes a multi-objective problem which is harder to solve.

The third objective function is minimization of material cost. The important assumption of most papers in this group is to assume that a fabric width is constant. So, minimization of fabric area used is equal to minimization of total fabric length used $[9,24]$. This objective function is used based on the insertion effect. This effect state that small-size parts can be inserted into gaps between large-size parts when they are assigned to the same marker. Subsequently, an amount of fabric used can be reduced. With this objective, planners try to combine different parts with various sizes into one marker. However, in [25], set of fabric rolls with different widths are used. This paper implicitly assumes that the total length of fabric used to satisfy demand is constant no matter what patterns are used. In this case, the total amount of fabric 
used can be reduced by trying to use a smaller width fabric rolls first. Moreover, a number of fabric rolls with each width is restricted to certain number.

The fourth objective function is minimization of set up plus material plus machine cost. The objective function in this group is divided into two subgroups which are 1.including machine cost and 2.not including machine cost. In the first subgroup, including machine cost, an objective function consists of material cost, set up cost, and machine cost [19]. As explained before, a machine cost is referred to an electricity cost occurred when using a computerized cutting machine. Moreover, this cost is proportional to length of fabric used for all markers. In the second subgroup, not including machine cost, an objective function consists of material cost and set up cost $[11,12,16]$. In this group, there are three forms of objective function found. Firstly, in [26], the author assumes that an amount of fabric used per lay is minimized when number of units/lay are maximized. Therefore, numbers of units/marker are fixed at maximum and, subsequently, fabric or material cost is eliminated from the objective. Secondly, in [12], the initial objective function is to minimize total cost composed of fabric cost, spreading cost, cutting cost, and increased marker making cost. In developing solution approach, the authors assume that fabric cost which is proportional to fabric length used is the most important cost. Cost components that don't relevant with the fabric length are eliminated from consideration. Therefore, only fabric cost remains in the objective function. Finally, in [20], the authors state that minimizing preparation cost which consists of minimizing material consumption, marker making cost, spreading and cutting cost is the most important in mark planning process.

In the development of new data systems that can efficiently collect data through a whole production line and subsequently, transform it into useful information. A collaborative planning concept can be applied to garment production line. With this concept, information such as due date, constraints and, etc, from downstream processes can be delivered to upstream processes. As a special case of applying this concept, due dates which is time information from cutting, sub-assembly and, assembly process can be included into mark planning process. In this case, a time-based objective component will be added to a single cost-based objective. Hence, an original single objective mark planning will become a multi-objective mark planning problem.

In the future when economic situation is improved, customers tend to require high quality fabrics which are relatively expensive. Such situation makes a material cost more important than any other relevant costs. As a result, excess and material cost can dominate other costs occurred in generating and using markers.

\subsection{Constraint}

Almost papers $[3,9,12,18-24,26]$ used only a set of basic constraints addressed in the basic mark planning model as shown in section 2.2. However, in $[16,17]$, they add a constraint that allows no excess to occur. To simplify the problem, Fister et al. [2] add an additional constraint used to represent a restriction on the maximum number of sizes allowed on each marker in each iteration. This constraint help reduce number of feasible solutions and amount of computation time. Lastly, in [27], a constraint used to limit an available time for cutting a set of markers is applied. This constraint expresses that a summary of preparation, spreading, and cutting time must be less than or equal to a demand time from a sewing process. Degraeve et al. [10] constrain on minimum number of stencils used for each size and lower, upper bound on number of stencils needed in one pattern to reduce number of pattern variables. As a result, when numbers of pattern variables are reduced, an amount of computation time is also reduced. In [23], a set of soft constraints which are used to express target goals in multi-objective problem is added.

With standard cutting equipment, i.e. hand knife and band knife, both lower and upper allowable ply height must be restricted. However, with laser cutting machine which is a new trend for garment industry, only upper allowable ply height must be included. This laser cutting machine can cut even one ply marker. Consequently, a solution search space is larger which results in larger number of alternative solutions. Nevertheless, a computation time is also significantly increased.

In [25], a constraint on the fabric stock available for each width is used to restricted number of fabric rolls of each width that can be selected. 


\subsection{Model Formulation}

Most of reviewed papers [2, 3, 9, 10, 16-18, 20-22, 24, 26, 27] are done based on the basic mark planning model. This model is in a type of integer nonlinear programming (INLP) which is relatively hard to solve. Nonlinear terms appeared in both objective and demand satisfaction constraints are the product of pattern or stencil assignment variable and ply height variable. To eliminate these nonlinear terms, Jacobs-blecha et al. [12] use the variable substitution method which substitutes the nonlinear terms with a variable $z_{j}$. Obviously, value of a variable $z_{j}$ is either 0 or a ply height of lay j. One important thing making this method work is that they use pattern assignment which generates all possible patterns outside the model. Apparently, these possible patterns are seen as only input of the model While in [21], they state that additional to nonlinearity, an area limitation constraint which is in a type of knapsack constraint makes the problem more complicated. To cope with the nonlinearlity, they use the variable discrete expansion which allows them to linearize the product of variables $a_{i j} z_{j}$ (number of units produced in each marker) by defining an additional set and variable. To cope with the knapsack constraint, they choose to reformulate to the network formulation. Many constraints are introduced to maintain the meaning of the original problem. In [2], the original mark planning model is transformed into knapsack model which known to be NP-hard problem [3]. Subsequently, they use knapsack-based concept to develop two heuristics to solve the transformed problem.

Degraeve et al. [10] tackle a difficulty in the original model by presenting 2 alternative models. In the first alternative, two decision variables are introduced, namely, $\mathrm{a}_{\mathrm{i}} \mathrm{p}_{\mathrm{j}}$ (binary) and $\mathrm{v}_{\mathrm{i}} \mathrm{p}_{\mathrm{j}}$ (integer). The major concept of this model is to assign size to empty positions in a marker and decide number of plies of that marker. Furthermore, this model is linearized by adding three new constraints into the model. To eliminate a vast amount of feasible solutions, they develop two sets of constraints that impose an ordering of sizes both within each pattern and across patterns. In the second alternative, two decision variables are introduced, namely, $\mathrm{y}_{(11, \ldots, \mathrm{jq})}$ (binary) and $\mathrm{z}_{(11, \ldots, \mathrm{jq})}$ (integer). The objective of this model is minimum total production. The major concept is to create possible patterns outside the model and use them as input to generate markers. Subsequently, each pattern is selected and numbers of layers of this pattern are decided.

\subsection{Solution Approach}

There are 2 types of methods used in solving this problem as shown in Table 6. Firstly, relaxation methods, the major purpose of methods in this group is to simplify the original problem. These methods try to relax or redefine decision variables or reformate the original problem to an easier-to-solve problem. Nevertheless, the simplified problems must keep the meaning of the original problem as much as possible. Secondly, optimization methods, the major purpose is to search for the best solution or good solution or a set of feasible solutions for the original problems or the simplified version. Some papers use both methods together while others used only solving method.

Table 6. The summary of solution approach methods.

\begin{tabular}{ll}
\hline \multicolumn{1}{c}{ The relaxation method } & \multicolumn{1}{c}{ The optimization method } \\
\hline 1. The variable discretization. & 1. The enumerative approach. \\
2. The variable substitution. & 2. The mathematical method. \\
3. The network or dynamic reformulation. & 3. The heuristic approach \\
4. The elimination by assumption. & 4. The meta-heuristic approach \\
5. The knapsack problem reformulation. & 5. The hybrid approach. \\
\hline
\end{tabular}

The relaxation methods are clearly explained in sub-section 4.1 and 4.3. Hence, this sub-section will dedicate only to the optimization methods.

To solve this problem mathematically, they firstly transform or reformulate the original model as explained in sub-section 4.3 into easier-to-solve model. Degraeve et al. [10, 21] try to mathematically solve this problem with three different models. Moreover, these three models are based on three different modelling concepts. The details of these three models are described previously in sub-section 4.3. 
The basic five heuristics based on constructive concept are developed in [9]. The first four algorithms (H1-H4) are inspired from rule of thumb used by experts of the garment industry whereas the last algorithm (H5) is a random search which randomly generates a set of markers satisfying demand orders.

Rose et al. [16] propose an enumerative approach based on branch and bound concept. The developed solution approach composes of two stages. Firstly, generating partitions, minimum number of markers and all possible combinations of plies for a set of full markers are calculated. Hence, output of this stage is a set of alternative empty markers. Secondly, all possible combinations are tested one by one to search for the best solutions. In this stage, branch and bound search tree is used to test each combination. There are two search strategies employed which are style distribution tree and marker filling tree. Any solutions that can completely branch to the last node are classified as feasible solutions. Jacobs-blecha et al. [12] develop three greedy heuristics to solve the transformed problem. Firstly, saving heuristic, assign size combination to a lay on the basis of the fabric saving achieved by combining them into one section. Secondly, cherry picking heuristic, build lays by combining certain sizes based on the best utilization of fabric. This algorithm picks the first and second most numerous quantity in the remaining order and places them in unfulfilled lays. Lastly, improvement heuristic, take a current solution and try to improve it by exchanging sizes in different sections or by combining existing sections into one section. Fister et al. also develop a greedy heuristic which its steps are 1.order the sizes in the work order, 2.pick the sizes one after another and 3.put them into the marker until reaching the maximum number of sizes $\left(\mathrm{m}^{\mathrm{k}}\right)$. Furthermore, this heuristic orders the sizes based on Cauchy-Schwartz inequality. In [23], decomposition concept is used to tackle this multiobjective problem. This concept tries to decompose the original problem into a set of smaller sub-problems. Subsequently, these sub-problems are sequentially solved to achieve a final solution corresponding with the original problem. The difficulty of using this concept is how to keep the core meaning of the original problem.

Genetic algorithm or evolutionary algorithm is a very popular meta-heuristic used in this area. Filipi et al. [19] develop two heuristics based on evolutionary algorithm (EA). Firstly, an EA with penalty function the concept is to assign lower fitness value to invalid solutions. As a result, fitness function in this approach is determined by subtracting the penalty term from the original objective function. Moreover, there are three types of penalty functions, i.e. logarithmic, linear and quadratic which are different in the growth rate of penalty. Secondly, an EA with repair function - the concept is to repair invalid solutions and, then, evaluate their fitness function again. Moreover, there are three repairing approaches used, i.e. heuristic, greedy and random. Martens [22] proposes two genetic algorithms (GA1 and GA2) based on two model which are integer nonlinear programming model (INLP) [21] and integer programming (IP) [10]. For GA1 (GA. based on the INLP. model), the penalty function consist of the amount of overproduction cost plus the amount of underproduction cost. Moreover, a dynamic penalty policy that regularly updates the penalty for demand underproduction is applied. For GA2 (GA. based on the IP. model), the penalty function compose of only the amount of overproduction cost. The next important issue is how to develop GA operators, for GA1, the authors use a uni-crossover operator together with a classic mutation operator. For GA2, an enhanced, schemata based one-and two-point crossover operator and a dynamic adaptation mutation are used. Furthermore, to boost up performance, auxiliary heuristics are developed for both GA1 and GA2. For GA1, a simple hill climbing algorithm is applied while for GA2, a network algorithm called "a flow redirection algorithm" is used. In [9], their initial population of individuals is a set of feasible solutions to CT which are generated with constructive algorithms H1-H4. In this approach, the best local position method (BLP) is used to assess the minimal length of every new or modified section.

Wonk et al. [27] propose two encoding methods which correspond with two different binary strings. Fister et al. [20] propose a hybrid self-adaptive evolutionary algorithm for marker optimization. To solve the problem, firstly, candidate solutions are randomly generated. All these solutions are either improved or repaired by the three modes of repairing, i.e. heuristic, random and greedy. The developed algorithm has 6 essential components as, i.e. representation of individuals, evaluation of the objective function and local search improvement, the population model, parent selection, mutation operator and neutral survival selection. Another variation of GA-based approach is presented in [3]. They develop a canonical GA approach which is a popular stochastic search technique. Moreover, their GA is divided into three major topics. Firstly, encoding chromosomes, a candidate solution or a size ratio will be encoded as an integer string to form a chromosome. Secondly, selection, the selection policy employed a combination of the roulette wheel selection and the elitism strategies. This combination can ensure higher fitness chromosomes become parents of new chromosomes. Lastly, cross over and mutation operations for mating chromosomes - uniform order based crossover method was used to execute crossover operation. Mutation 
operator is equipped to search global optima in the solution space with the mutation probability equal to 0.1 .

Simulate annealing (SA) which is a flexible and robust stochastic search is applied in [9]. This approach starts from an initial solution and, then, moves to a neighbor in hope of further improving the current solution. Furthermore, there are two types of neighbor with respect to the objective function value that are a neighbor that can improve the objective value and vice versa. This iterative process continues until the stopping criterion is reached. In this research, the SA process is stopped after three successive plateaus without improvement of the current solution.

In hope of solving this problem more efficient, many combined GA are developed. In [17], the hybrid approach which is a combination of of a conventional heuristic method and a standard GA. The aim of combining these two methods is to reduce number of initial populations and also amount of execution time. At first, they use a conventional heuristic to generate a suggested size ratio which will be used as encoding mask string in generating initial population for GA. With this encoding mask string, number of initial populations represented as chromosomes will be reduced. Okuno et al. [24] propose a genetic annealing (GAn) method which is a combination of a genetic algorithm (GA) and a simulate annealing (SA). At first, GA is used to generate solutions with the best possible fitness value. Subsequently, SA Which is a local search concept is applied to improve the solutions. In SA Stage, a concept of uphill moves which allows moves from a current solution to a neighbor in hope that it leads to a minimal cost one. M'Hallah et al. [9] also develop a genetic annealing (GAn) method. This approach can be seen as a modification of GA because the main structure is based on GA except a replacement strategy and a mutation mechanism. These modifications accelerate the search without leading it to premature convergence and stagnation in local minimum.

In purpose of solving larger-size problem, Deng et al. [18] present the two stages optimization method based on probability search and genetic algorithm to solve cut order planning (COP) problem. The major concept is to decompose the original COP problem into three sub-problems which each sub-problem corresponds with only one decision variable. In the first stage, there are two related sub-problems. The first sub-problem is to determine number of markers or cutting tables. The second sub-problem is used to randomly generate number of layers for each cutting table. In the second stage, sizes combinations are randomly generated for each cutting table based on the solutions from the first stage. The final solutions are feasible with respect to both a maximum allowable cutting table length limitation and a demand satisfaction constraint.

In literatures, there are two assignment units found, i.e. stencil and pattern assignment units. With these two units, all parts required for each produced item are restricted to locate on the same marker. Furthermore, these two units are not only used in academic researches but also used in practice. The reason is mainly related to an intermittently distribute of fabric color. In the future, if a new efficient and effective dying technology which can produce uniformly colour-distributed fabric is developed, a part assignment unit can be an alternative in generating markers. With part assignment unit, all required parts are independently assigned to any generated markers. As described earlier, with this method, there is a great chance to create better fit marker patterns. Hence, a number of markers used and amount of fabric area used are hoped to be reduced with better fit marker patterns.

\subsection{Performance Measurement}

To measure performance of the developed models and methods, computational experiments must be conducted. There are two major issues in designing experiments.

Firstly, a source of problem instances, there are three sources as follows:

Table 7. Sources of problem instances.

\begin{tabular}{lc}
\hline \multicolumn{1}{c}{ Sources } & Papers \\
\hline 1. Problem instances from real-world industry. & {$[2,3,9,12,17,19-21,27]$} \\
2. Problem instances from program generating & {$[22,26]$} \\
3. Problem instances from other papers & {$[9,16]$} \\
\hline
\end{tabular}

Secondly, a lower bound, there are 4 types of lower bound used to compare as follows: 
Table 8. Types of lower bound.

\begin{tabular}{lc}
\hline \multicolumn{1}{c}{ Type of lower bound } & Papers \\
\hline 1. Compare with lower bounds from a commercial software & {$[3,9,12,17,19,24,26,27]$} \\
2. Compare with lower bounds from other heuristics & {$[10,12,17,19-22]$} \\
3. Compare with optimal solution & {$[22]$} \\
4. Compare with solutions from an expert & {$[2]$} \\
\hline
\end{tabular}

Finally, to facilitate readers, all reviewed mark planning papers are summarized into Table 9 with respect to their objective functions, model formulations and, solution approaches as shown below. In this table, the research papers are arranged with respect to their published years. Furthermore, in model formulation column, the basic mark planning model is referred to the mark planning model presented in section 2.2.

Table 9. A summarization of mark planning papers.

\begin{tabular}{|c|c|c|c|c|c|c|c|}
\hline \multirow[b]{2}{*}{ Year } & \multirow[b]{2}{*}{ Reference } & \multicolumn{4}{|c|}{$\begin{array}{l}\text { Objective } \\
\text { function }\end{array}$} & \multirow[b]{2}{*}{ Model formulation } & \multirow[b]{2}{*}{ Solution approach } \\
\hline & & 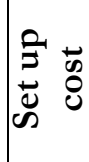 & 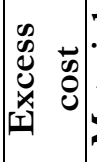 & 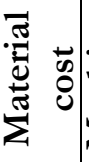 & 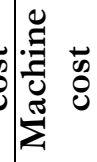 & & \\
\hline 1976 & Howard S. Coff[25] & & & $\checkmark$ & & $\begin{array}{l}\text { The nonlinear mark } \\
\text { planning model with } \\
\text { the fabric stock } \\
\text { available constraint. }\end{array}$ & $\begin{array}{l}\text { A mathematical methods } \\
\text { and a branch and bound } \\
\text { based approach. }\end{array}$ \\
\hline 1991 & $\begin{array}{l}\text { Jane C. Ammons, } \\
\text { et.al.[4] }\end{array}$ & $\checkmark$ & & $\checkmark$ & $\checkmark$ & $\begin{array}{l}\text { The basic and } \\
\text { linearized mark } \\
\text { planning model. }\end{array}$ & 3 heuristic approaches. \\
\hline 1997 & $\begin{array}{c}\text { Jacobs-Blecha, C., et } \\
\text { al.[12]. }\end{array}$ & & & $\checkmark$ & & $\begin{array}{l}\text { The linearized mark } \\
\text { planning model. }\end{array}$ & $\begin{array}{l}3 \text { greedy heuristic } \\
\text { approaches. }\end{array}$ \\
\hline 1998 & $\begin{array}{l}\text { Degraeve, Z. and M. } \\
\text { Vandebroek [21]. }\end{array}$ & $\checkmark$ & $\checkmark$ & & & $\begin{array}{l}\text { The basic mark } \\
\text { planning model. }\end{array}$ & A mathematical method. \\
\hline 1998 & $\begin{array}{l}\text { Rosenblueth, } \\
\text { D.A.[26]. }\end{array}$ & $\checkmark$ & & $\checkmark$ & & $\begin{array}{l}\text { The basic mark } \\
\text { planning model. }\end{array}$ & $\begin{array}{l}\text { A branch and bound } \\
\text { based approach. }\end{array}$ \\
\hline 2002 & $\begin{array}{l}\text { Degraeve, Z., W. } \\
\text { Gochet, and R. } \\
\text { Jans[10]. }\end{array}$ & $\checkmark$ & $\checkmark$ & & & 2 alternative models. & A mathematical method. \\
\hline 2004 & Martens, J[22]. & $\checkmark$ & $\checkmark$ & & & $\begin{array}{l}\text { The basic mark } \\
\text { planning model. }\end{array}$ & $\begin{array}{c}\text { Two genetic algorithm } \\
\text { approaches. }\end{array}$ \\
\hline 2006 & Filipi, B., et al.[19]. & $\checkmark$ & & & & $\begin{array}{l}\text { The basic mark } \\
\text { planning model. }\end{array}$ & $\begin{array}{l}\text { Two evolutionary } \\
\text { algorithm based } \\
\text { approaches. }\end{array}$ \\
\hline 2007 & Okuno, H., et.al.[24]. & & & $\checkmark$ & & $\begin{array}{l}\text { The basic mark } \\
\text { planning model. }\end{array}$ & $\begin{array}{l}\text { A genetic annealing } \\
\text { approach. }\end{array}$ \\
\hline
\end{tabular}




\begin{tabular}{|c|c|c|c|c|c|c|c|}
\hline \multirow[b]{2}{*}{ Year } & \multirow[b]{2}{*}{ Reference } & \multicolumn{4}{|c|}{$\begin{array}{l}\text { Objective } \\
\text { function }\end{array}$} & \multirow[b]{2}{*}{ Model formulation } & \multirow[b]{2}{*}{ Solution approach } \\
\hline & & $\begin{array}{ll}0 & \\
\vdots & 0 \\
\tilde{D} & 0 \\
\infty & 0\end{array}$ & 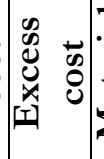 & & 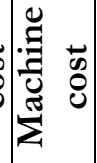 & & \\
\hline 2007 & $\begin{array}{l}\text { Rose, D.M. and D.R. } \\
\text { Shier[16]. }\end{array}$ & $\checkmark$ & & & & $\begin{array}{l}\text { The basic mark } \\
\text { planning model. }\end{array}$ & $\begin{array}{c}\text { An enumerative } \\
\text { approach based on } \\
\text { branch and bound } \\
\text { method. }\end{array}$ \\
\hline 2008 & $\begin{array}{l}\text { Fister, I., M. Mernik, } \\
\text { and B. Filipic[2]. }\end{array}$ & $\checkmark$ & & & & $\begin{array}{l}\text { The transformed } \\
\text { knapsack model. }\end{array}$ & $\begin{array}{c}\text { Evolutionary algorithms } \\
\text { based approach. }\end{array}$ \\
\hline 2008 & $\begin{array}{l}\text { Wong, W.K. and } \\
\text { S.Y.S. Leung[27]. }\end{array}$ & $\checkmark$ & & $\checkmark$ & $\checkmark$ & $\begin{array}{l}\text { The basic mark } \\
\text { planning model. }\end{array}$ & $\begin{array}{l}\text { A genetic algorithm } \\
\text { approach. }\end{array}$ \\
\hline 2010 & $\begin{array}{l}\text { Fister, I., M. Mernik, } \\
\text { and B. Filipic[20]. }\end{array}$ & $\checkmark$ & & & & $\begin{array}{l}\text { The basic mark } \\
\text { planning model. }\end{array}$ & $\begin{array}{l}\text { A modified genetic } \\
\text { algorithm approach. }\end{array}$ \\
\hline 2011 & Deng, H., et al.[18]. & $\checkmark$ & & & & $\begin{array}{l}\text { The basic mark } \\
\text { planning model. }\end{array}$ & $\begin{array}{l}\text { The two stages } \\
\text { optimization method. }\end{array}$ \\
\hline 2012 & $\begin{array}{l}\text { R. P. Abeysooriya, } \\
\text { T.G.I.F.[3]. }\end{array}$ & $\checkmark$ & & & & $\begin{array}{l}\text { The basic mark } \\
\text { planning model. }\end{array}$ & $\begin{array}{l}\text { A canonical genetic } \\
\text { algorithm approach. }\end{array}$ \\
\hline 2012 & $\begin{array}{l}\text { R. P. Abeysooriya, } \\
\text { T.G.I.F.[17]. }\end{array}$ & $\checkmark$ & & & & $\begin{array}{l}\text { The basic mark } \\
\text { planning model. }\end{array}$ & A hybrid approach \\
\hline 2013 & $\begin{array}{l}\text { Puasakul, K. and P. } \\
\text { Chaovalitwongse.[23]. } \\
\text { *due date based objective } \\
\text { component is applied in } \\
\text { this paper. }\end{array}$ & $\checkmark$ & $\checkmark$ & & & $\begin{array}{l}\text { The basic mark } \\
\text { planning model. }\end{array}$ & A heuristic approach. \\
\hline 2013 & $\begin{array}{c}\text { Wong, W.K., S.Y.S. } \\
\text { Leung, and Z.X. } \\
\text { Guo.[11]. }\end{array}$ & $\checkmark$ & & $\checkmark$ & & $\begin{array}{l}\text { The basic mark } \\
\text { planning model. }\end{array}$ & $\begin{array}{c}\text { Evolutionary algorithms } \\
\text { based approach. }\end{array}$ \\
\hline 2014 & $\begin{array}{l}\text { M'Hallah, R. and A. } \\
\text { Bouziri[9]. }\end{array}$ & & & $\checkmark$ & & $\begin{array}{l}\text { The basic mark } \\
\text { planning model. }\end{array}$ & $\begin{array}{l}\text { Genetic algorithm, } \\
\text { simulate annealing, and } \\
\text { Genetic annealing } \\
\text { approaches. }\end{array}$ \\
\hline
\end{tabular}

\section{The Relationship between Objective Functions and Major Garment Characteristics}

As described previously, all objective functions of mark planning papers found are cost-based objective which can be categorized into 4 groups, namely, 1 .set up cost, 2 .set up plus excess cost, 3.material cost, and 4.set up plus material plus machine cost.

Important aspects that should be explored are what is the cost driver of each cost component and how they control the value of each cost? From both literature and industrial survey, it is found that the major garment characteristics presented before play the role of cost drivers for all considered costs. Hence, it is worthwhile to study the relationship between each objective function which is a combination of costs and a 
set of garment characteristics. In this section, the relationship, how cost drivers control value of each cost, and how to generate mark planning that correspond with each combination of characteristics are presented.

The benefit of this section is to tell readers what are cost drivers for each cost combination. This will help readers successfully control each cost combination. On the other hand, these relations will tell readers what costs are most probably occurred when facing with any combination of characteristics.

Table 10. The relation between objective functions and a set of major garment characteristics.

\begin{tabular}{lcccc}
\hline \multicolumn{1}{c}{ Objective function } & $\begin{array}{c}\text { Demand } \\
\text { volume }\end{array}$ & $\begin{array}{c}\text { Variation of } \\
\text { demand } \\
\text { between parts }\end{array}$ & Price of fabric & $\begin{array}{c}\text { Number of } \\
\text { parts per unit } \\
\text { of product }\end{array}$ \\
\hline 1.Minimize set up cost & high & smooth & low & low \\
\hline $\begin{array}{l}\text { 2.Minimize set up and excess } \\
\text { cost }\end{array}$ & medium & Non-smooth & high & low \\
\hline 3.Minimize material cost & low & smooth & high & high \\
\hline $\begin{array}{l}\text { 4.Minimize set up, material, and } \\
\text { machine cost }\end{array}$ & high & smooth & high & high \\
\hline
\end{tabular}

In objective 1, set up cost, high demand volume certainly results in large number of markers used. When demand variation is smooth, excess part is not likely to occur. Together with low price of fabric, excess cost and material cost are unimportant to manufacturers in this group. As stated before, material cost can be reduced only when small parts can be inserted with large parts. However, when number of parts is low, the insertion between small parts and large parts are not likely to occur. So, material cost is not included into the objective function. In this group, manufacturers usually produce low price product with low cost fabric. Their customer orders usually come in huge lot size with a smooth demand pattern. This combination of characteristics is related to mass production manufacturers. To minimize this objective, manufacturers try to use as minimum as possible number of markers. Subsequently, marker area should be highly utilized and a max number of plies should be used. Many parts with different sizes and shapes have to be combined together.

In objective 2, set up and excess cost, when non-smooth demand character combines with high price fabric character, excess cost becomes importance to manufacturers. Set up cost still plays important role because medium demand volume still require many markers to satisfy demand. Again, low number of parts character makes material cost useless to include into the objective function. Products in this group are high price items which are usually made from high cost fabrics. Their customer orders usually come in medium lot size with a non-smooth demand pattern. Additionally, this combination of characteristics can occur with fashion-product manufacturers. The non-smoothness of demand together with the use of high price fabrics makes excess cost more important. Hence, in this scenario, an objective consists of set up plus excess cost. To minimize this objective, manufacturers have to trade-off between these two costs to find the minimum total cost solution. In this context, some marker areas may not be fully utilized. Furthermore, ply height of some markers may not reach to the maximum allowable height.

In objective 3, material cost, low demand volume results in small number of markers used. So, set up cost which depends on number of markers is not important. Furthermore, excess cost is not important with smooth demand which has low possibility of excess to occur even in the situation that fabric cost is high. The combination of high fabric price character and high number of parts character makes material cost more important. With variety of parts, insertion between parts can be happened. Therefore, material cost obviously dominates all other relevant costs. Products in this group are made from high cost fabrics and are complex which composes of number of parts with many shapes and sizes. Their demand volumes are low and a pattern is smooth. This combination usually occurs in the fashion-product industry. In this scenario, set up cost is relatively small compared to the cost of material. Therefore, set up cost is neglected from the consideration. To minimize material cost, planners try to use the minimum amount of fabrics which are represented in terms of fabric length. Especially with complex products, small parts can be inserted into gaps between large parts which can reduce the total length of fabric used. 
In objective 4, set up material and machine cost, demand in this group is relatively smooth so excess has less chance to occur. Apparently, high demand volume results in both set up cost corresponding with number of markers used and machine cost corresponding with cutting machines used in cutting process. Similar to category 3, high price fabric and high number of parts make material cost more important. Therefore, material cost is included into objective function. Products in this group are made from high cost fabrics and are complex. Moreover, these products are usually global well-known brands. Their demand volumes are high and the pattern is relatively smooth. Due to high demand volume, manufacturers, have two ways to deal with a cutting process. Firstly, they choose to invest in a computerized cutting machine which can cut out parts faster and more accuracy than a manual method. As a result, the objective function should compose of set up cost, material cost and machine cost. Secondly, manufacturers still use a manual method to cut out parts. With this method, the objective function should not incur machine cost. Although, fabric cost is high, excess cost is neglected because the smooth demand pattern can help reduce a possibility of excess to occur. As a result, numbers of excesses are very small compared to the demand volume. This combination of characteristics usually belongs to mass production manufacturers who produce the global brand products. To minimize this objective function, planners should try to use the minimum number of markers which each marker's area is fully utilized. Moreover, small-size parts should be combined with large-size parts. Finally, as maximum as possible number of plies should be used in this scenario.

\section{Conclusion}

In summary, there are two types of solution approaches deployed: the relaxation methods, the purpose of this method is to simplify the original problems into more tractable problems. However, these simplified problems must be able to keep the core meaning of the original problem, and the optimization methods, the purpose of this method is to search for solutions that correspond with the original problem. Moreover, these solving methods can be used to solve both the original and the simplified versions.

An enumerative approach is a basic and easy-to-understand approach used to find all feasible solutions. Unfortunately, this method can solve only small size problems To cope with larger-size problem, many papers develop heuristic approaches based on both a specific structure and general heuristic concepts, e.g. greedy, cherry picking, genetic algorithm, simulate annealing, etc. These heuristics can solve mark planning problem with higher efficiency. Additionally, among these heuristics, genetic algorithm is more popular than any other heuristic concepts used. In hope of solving this problem more efficient, hybrid approaches which combine two selected heuristics are proposed, e.g. genetic annealing, genetic algorithm combined with a specific heuristic. These hybrid approaches perform on the average better than the other two previous types.

Almost all reviewed papers are done based on three aspects as follows:

(1) Area of units assigned to markers to create marker patterns are assumed to be equal for all sizes.

(2) Only stencils and patterns are used as assignment units.

(3) Most papers are developed based on a separate planning concept which independently determines mark planning without concerning all other relevant processes.

Therefore, future researches can be extended in three ways. Firstly, part assignment can be used instead of pattern and stencil assignment. With part assignment, marker areas are, in some cases, used with higher efficiency. As a result, number of markers used to satisfy a customer demand can be reduced. Secondly, to correspond with real-world industry, parts or units from different sizes should have different areas. The original mark planning problem will be further complicated when these areas are different. Finally, future researches should emphasize on the integration between mark planning process and other relevant processes. The integration can be done with either previously processes, e.g. product design, purchasing, etc. or latter processes, e.g. marker making, sewing, etc. Moreover, the levels of integration are relatively varied depending on planner's decisions. For example, in some cases, only data from other relevant processes are included whereas, in some cases, mark planning is combined with other processes to form a new larger problem that can cover a wider range of production decision. In case of time information, e.g. due date, production start date, from downstream processes are included into mark planning process, a single objective function will become a multi-objective function which is a current trend for mark planning problem. This trend is a consequence of three factors which are a development of efficient data collection system, an emerging of collaborative planning concept and, a higher competitive environment. However, 
this trend is at a beginning period. So, very few multi-objective mark planning papers are published. Nevertheless, multi-objective production planning model for a garment factory [28] is presented as an example of applying multi-objective concept to garment processes. They develop multi-objective production planning model for a sewing process. In this paper, four objective components are introduced, i.e. minimization of lateness, minimization of underachievement revenue, minimization of over production cost and, minimization of overtime. To solve this problem, they use the sequential linear goal programming (SLGP) algorithm which sequentially solve each objective by their priorities. This paper reminds researchers who interest in this area that there are other aspects of objective which should be concerned in garment industry.

\section{References}

[1] W. K. Wong, S. Y. S. Leung, and K. F. Au, "Real-time GA-based rescheduling approach for the presewing stage of an apparel manufacturing process," The International Journal of Advanced Manufacturing Technology, vol. 25, no. 1-2. pp. 180-188, 2005.

[2] I. Fister, M. Mernik, and B. Filipic, "Optimization of markers in clothing industry," Engineering Applications of Artificial Intelligence, vol. 21, no. 4, p. 669-678, 2008.

[3] R. P. Abeysooriya and T. G. Fernando, "Canonical genetic algorithm to optimize cut order plan solutions in apparel manufacturing," Journal of Emerging Trends in Computing and Information Sciences, vol. 3, no. 2, pp. 150-154, 2012.

[4] J. C. Ammons, C. Jacobs-Blecha, T. Smith, A. Baker, and B. Warden, "Cut order planning," Short Term Task, Final Report, Georgia Institute of Technology, 1991.

[5] S. Zezova, G. Demboski, and V. Panov, "Optimization of technological process of cutting by use of software applications for cut order planning," Tekstil i obleklo, vol. 3, pp. 77-79, 2013.

[6] W. K. Wong and S.Y.S. Leung, "A hybrid planning process for improving fabric utilization," Textile Research Journal, vol. 79, no. 18, pp. 1680-1695, 2009.

[7] J. Solinger, Apparel Manufacturing Handbook: Analysis, Principles and Practice, 2nd ed. Bobbin Media Corporation, 1988.

[8] S. Benjaafar and M. Sheikhzadeh, "Batch sizing models for flexible manufacturing cells," submitted for publication.

[9] R. M'Hallah and A. Bouziri, "Heuristics for the combined cut order planning two-dimensional layout problem in the apparel industry," International Transactions in Operational Research, vol. 23, no. 1-2, pp. 321-353, 2016.

[10] Z. Degraeve, W. Gochet, and R. Jans, "Alternative formulations for a layout problem in the fashion industry," European Journal of Operational Research, vol. 143, no. 1, pp. 80-93, 2002.

[11] W. K. Wong, Z. X Guo, and S. Y. S. Leung, "Optimizing cut order planning in apparel production using evolutionary strategies," in Optimizing Decision Making in the Apparel Supply Chain Using Artificial Intelligence (AI). Woodhead Publishing, 2013, pp. 81-105.

[12] C. Jacobs-Blecha, J. C. Ammons, A. Schutte, and T. Smith, "Cut order planning for apparel manufacturing," IIE Transactions, vol. 30, no. 1, pp. 79-90, 1997.

[13] A. A. Farley, "Mathematical programming models for cutting-stock problems in the clothing industry," The Journal of the Operational Research Society, vol. 39, no. 1, p. 41-53, 1988.

[14] D. Pisinger, "An exact algorithm for large multiple knapsack problems," European Journal of Operational Research, vol. 114, no. 3, pp. 528-541, 1999.

[15] M. R. Jones, "Identifying the small apparel manufacturer: A typology of manufacturing strategies," Ph.D. dissertation, Virginia Polytechnic Institute and State University, 1999.

[16] D. M. Rose and D. R. Shier, "Cut scheduling in the apparel industry," Comput. Oper. Res., vol. 34, no. 11, pp. 3209-3228, 2007.

[17] R. P. Abeysooriya and T. G. Fernando, "Hybrid approach to optimize cut order plan solutions in apparel manufacturing," International Journal of Information and Communication Technology Research, vol. 2, no. 4, pp. 348-353, 2012.

[18] L. Yan-mei, Y. Shao-cong, and Z. Shu-ting, "Research on cut order planning for apparel mass customization," in Emerging Research in Artificial Intelligence and Computational Intelligence, H. Deng, D. Miao, F. L. Wang, and J. Lei, Eds. Springer Berlin Heidelberg, 2011, pp. 267-271. 
[19] B. Filipič, I. Fister, and M. Mernik, "Evolutionary search for optimal combinations of markers in clothing manufacturing," in Proceedings of the 8th Annual Conference on Genetic and Evolutionary Computation, 2006, ACM, Seattle, Washington, USA, pp. 1661-1666.

[20] I. Fister, M. Mernik, and B. Filipič, "A hybrid self-adaptive evolutionary algorithm for marker optimization in the clothing industry," Applied Soft Computing, vol. 10, no. 2, pp. 409-422.

[21] Z. Degraeve and M. Vandebroek, "A mixed integer programming model for solving a layout problem in the fashion industry," Management Science, vol. 44, no. 3, pp. 301-310, 1998.

[22] J. Martens, "Two genetic algorithms to solve a layout problem in the fashion industry," European Journal of Operational Research, vol. 154, no. 1, pp. 304-322, 2004.

[23] K. Puasakul and P. Chaovalitwongse, "The development of heuristic for solving multi objective mark planning problem in garment industry," in Proc. IEEE International Conference on Industrial Engineering and Engineering Management (IEEM), 2013, pp. 743-747.

[24] A. Bouziri and R. M'hallah, "A hybrid genetic algorithm for the cut order planning problem," in New Trends in Applied Artificial Intelligence, H. G. Okuno and M. Ali, Eds. Springer Berlin Heidelberg, 2007, p. 454-463.

[25] H. S. Coff, "Cut scheduling for optimum fabric utilization in apparel production," M.S. thesis, Georgia institute of technology, 1976.

[26] D. A. Rosenblueth, "A prolog program for decomposing clothing orders into lays," SIGAPP Appl. Comput. Rev., vol. 6, no. 1, pp. 26-32, 1998.

[27] W. K. Wong and S. Y. S. Leung, "Genetic optimization of fabric utilization in apparel manufacturing," International Journal of Production Economics, vol. 114, no. 1, pp. 376-387, 2008.

[28] M. T. Tabucanon and M. D. E. Estraza, "Multi-objective production planning model for a garment factory," International Journal of Clothing Science and Technology, vol. 1, no. 3, pp. 26-30.1989. 